\title{
Development and Validation of a LC-ESI-MS/MS Based Bioanalytical Method for Dapagliflozin and Saxagliptin in Human Plasma
}

\author{
Swapna Goday ${ }^{1 *}$, Abdul Rahaman Shaik1, Prameelarani Avula² \\ ${ }^{1}$ Department of Pharmaceutical Analysis, Nirmala College of Pharmacy and Research Scholar JNTUK, Kakinada, Andhra Pradesh, \\ INDIA. \\ ${ }^{2}$ Department of Pharmaceutics, University College of Pharmaceutical Sciences, Acharya Nagarjuna University Guntur, Andhra Pradesh, \\ INDIA.
}

\begin{abstract}
Objective: To develop a new, rapid and sensitive LC-ESI -MS/MS method for the simultaneous estimation of Dapagliflozin and saxagliptin in human $\mathrm{K}_{2}$ EDTA plasma by Liquid -liquid Extraction method (LLE) using deutereated dapagliflozin (DGd2) and saxagliptin (SGd5). Method: Chromatographic separation was carried out on a reverse phase hypersil Gold $\mathrm{C}_{18}(50 \mathrm{~mm} \times 3.0 \mathrm{~mm}, 5 \mu \mathrm{m})$ column using mixture of $10 \mathrm{mM}$ Ammonium acetate and methanol $(20: 80, v / v)$ at a flow rate of $0.5 \mathrm{ml} / \mathrm{min}$ in isocratic mode. Quantification was achieved using an electro spray ion interface operating in positive mode, under multiple reaction monitoring (MRM) conditions. Results: The method showed excellent linearity over the concentration range of $50.00-10000.00 \mathrm{pg} / \mathrm{mL}$ for both the analytes. The intrabatch and inter batch precision ( $\% \mathrm{CV}$ ) was $\leq 4.5 \%$ and Matrix effect ( $\% \mathrm{CV}$ ) was $1.27 \%$, $1.20 \%$ for both the analytes. Conclusion: The simplicity of the method allows for application in laboratories, presents a valuable tool for bioavailability, bioequivalence, pharmacokinetic studies.
\end{abstract}

Key words: Application to pk profile studies, Method development, Validation, Dapagliflozin, Saxagliptin, LC-ESI-MS/MS.

\section{INTRODUCTION}

Type 2 diabetes is an enduring complication in which blood glucose can no longer be handled. When the cells change into insulin resistant, it feel necessity for more and more insulin to shift sugar into the cells and too much sugar stays in the blood. ${ }^{1}$ Dapagliflozin is a sodium-glucose co transporter 2 inhibitor, which inhibits glucose retention in the kidney. Chemical name Dapagliflozin is $(2 \mathrm{~S}, 3 \mathrm{R}, 4 \mathrm{R}, 5 \mathrm{~S}, 6 \mathrm{R})-2-\{4-$ chloro 3(4ethoxyphenyl)methyl]phenyl (hydroxymethyl) oxane-3,4,5-triol. It has a molecular formula of $\mathrm{C} 21 \mathrm{H} 25 \mathrm{ClO} 6$ and a molecular weight of 408.13. Saxagliptin is an orally effective hypoglycaemic of the advanced dipeptidylpeptidase-4 (DPP-4) inhibitor class of drugs. Chemical name for Saxagliptin is (1S, 3S, 5S)-2-[(2S)-Amino (3-hydroxytricyclo [3.3.1.1(3, 7)] dec-1-yl) acetyl]-2-azabicyclo [3.1.0] hexane-3-carbonitrile mono hydrochloride. It has a molecular formula of $\mathrm{C} 18 \mathrm{H} 26 \mathrm{ClN} 3 \mathrm{O} 2$ and a molecular weight of $351.8 .^{2} \mathrm{Few}$ methods disclosed are dapagliflozin active pharmaceutical ingredient chromatographic method was carried out by potassium dihydrogen phosphate and acetonitrile. ${ }^{3}$ Validated LC-MS/MS methods for the determination of dapagliflozin, a sodium-glucose co-transporter 2 inhibitor in normal and ZDF rat plasma. ${ }^{4}$ simultaneous estimation of dapagliflozin in api and pharmaceutical dos age form by development and stability indicating HPLC method. ${ }^{5}$ The analyte chromatography was carried by buffer and acetonitrile. ${ }^{6}$ LC-MS/MS investigation of metformin,
Submission Date: 05-12-17; Revision Date: 13-04-18; Accepted Date: 17-05-18

DOI: 10.5530/ijper.52.4s.108 Correspondence: Swapna Goday, Department of Pharmaceutical Analysis, Nirmala College of Pharmacy and Research Scholar, JNTUK, Kakinada, Andhra Pradesh, INDIA. Phone: 8121226766 E-mail: swapna.goday.gs@ gmail.com

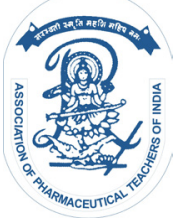

www.ijper.org 
saxagliptin and 5-hydroxy saxagliptin in human plasma and its pharmacokinetic study with a fixed-dose formulation in healthy Indian subjects. ${ }^{7}$ Stability indicating RP-LC-PDA method for the quantitative analysis of saxagliptin in pharmaceutical dosage form. ${ }^{8}$ Development of a rapid UPLC-MS/MS method for quantification of saxagliptin in rat plasma and application to pharmacokinetic study. ${ }^{9}$ Bio analytical method validation includes all of the procedures demonstrate that method is for biological sample. ${ }^{10}$ The method involves methanol and phosphate buffer. ${ }^{11}$ Stability-Indicating Liquid Chromatographic Method for Determination of Saxagliptin and Structure Elucidation of the Major Degradation Products Using LC-MS. ${ }^{12}$ A New RP-HPLC Method Development and Validation of Dapagliflozin in Bulk and Tablet Dosage Form. ${ }^{13}$ Stability indicating RP-HPLC method development and validation for estimation of dapagliflozin and metformin hcl. ${ }^{14} \mathrm{~A}$ mixture of acetonitrile and orthophosphoric acid is used in method. ${ }^{15}$ Development and validation of a RP-HPLC method for the estimation of dapagliflozin in api. ${ }^{16} \mathrm{~A}$ rapid and sensitive LC-MS/MS assay for the determination of saxagliptin and its active metabolite 5-hydroxy saxagliptin in human plasma and its application to a Pharmacokinetic study. ${ }^{17}$ Acetonitrile and ammonium formate buffer is used for resolution of drugs. ${ }^{18}$ Stability indicating validated RP-HPLC technique for the analysis of multi component anti-diabetic drug combos in pharmaceutical dosage forms. ${ }^{19}$ The chromatographic separation was achieved by sodium dihydrogen phosphate buffer and acetonitrile. ${ }^{20}$ Positive ionization with multiple reactions monitoring by mass spectrometer. ${ }^{21}$

Literature survey reveals that there are no methods reported for simultaneous estimation of dapagliflozin and saxagliptin by any chromatographic methods. Hence, the main objective of the present work was to develop a simple bio analytical method for simultaneous estimation of dapagliflozin and saxagliptin from human plasma and its application to bioavailability, bioequivalence and pharmacokinetics with consideration of accuracy, sensitivity, rapidity, economy, selectivity, stability studies by US-FDA guidelines.

\section{MATERIALS AND METHODS}

\section{Chemicals and Reagents}

The drugs Dapagliflozin, Saxagliptin, Dapagliflozind5 and Saxagliptin $\mathrm{d} 2$ were purchased as a gift samples from Symed labs, Hyderabad, India and Toronto research chemicals, Canada. Ethyl acetate, HPLC grade methanol and acetonitrile were obtained from J.T. Baker USA. Sodium dihydrogen phosphate $\left(\mathrm{NaH}_{2} \mathrm{PO}_{4}\right.$, reagent grade), Ammonium acetate (reagent grade) was acquired from Merck Limited, Worli, Mumbai. Human plasma was procured from Doctors labs, Hyderabad, India. Ultra-pure water from MilliQ-system (Millipore) was used throughout the investigation.

\section{Equipment}

An API 4000 HPLC-ESI-MS/MS system (Applied Bio systems), 1200 Series HPLC system (Agilent Technologies, Waldron, Germany), data acquisition and processing were adept using Analyst ${ }^{\circledR}$ Software 1.4.1. The chromatographic separation of the analytes was accomplished at $30^{\circ} \mathrm{C}$ applying Hypersil Gold $\mathrm{C}_{18}(50 \mathrm{~mm} \times 3.0 \mathrm{~mm}$, $5 \mu \mathrm{m})$ column. A mixture of $10 \mathrm{mM}$ ammonium acetate: Methanol $(20: 80 \mathrm{v} / \mathrm{v})$ was used as mobile phase. $0.5 \mathrm{~mL} / \mathrm{min}$ and injection volume of $20 \mu \mathrm{L}$. Triple quadruple mass spectrometer equipped with electro spray ionization and handled in positive ionization mode for tracking down and quantification of analytes and internal standards. The intensification of the source and compound parameters are Declustering potential: $40 \mathrm{~V}$, entrance potential: $10 \mathrm{~V}$, exit Potential: 7 , collision energy: $15 \mathrm{~V}$ for Dapagliflozin and 16V for Saxagliptin .The source criteria were optimized as collision gas: 5 , ion spray voltage: $5500 \mathrm{~V}$ and temperature: $550^{\circ} \mathrm{C}$.

\section{Preparation of calibration standards and quality control samples}

Standard Stock solutions of DG $\left(100.0 \mu \mathrm{g} \cdot \mathrm{mL}^{-1}\right)$, DGd5

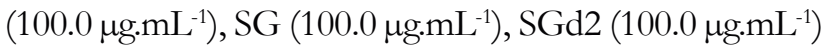
were processed in methanol. From respective stock solution $100.0 \mathrm{ng} \cdot \mathrm{mL}^{-1}$ intermediate dilution was prepared in plasma. Aliquots of $100.0 \mathrm{ng} \cdot \mathrm{mL}^{-1}$ were used to transfix blank human plasma in order to achieve calibration curve standards of 50.0, 100.0, 500.0, 1000.0, 2000.0, $4000.0,6000.0,8000.0,10000.0 \mathrm{pg} / \mathrm{mL}$. Four levels of QC concentrations at 50.0, 150.0, 3000.0 and 7000.0 $\mathrm{pg} / \mathrm{mL}$ (LLOQ, LQC, MQC and HQC) were prepared by adopting the different plasma.DGd5 and SGd2was diluted to $10.0 \mathrm{ng} \cdot \mathrm{mL}^{-1}$ (Spiked concentration of internal standard) using $50 \%$ methanol and stored in the refrigerator $2-8^{\circ} \mathrm{C}$ until analysis.

\section{Sample preparation for analysis}

Liquid-liquid extraction was carried out to extract the drug and IS for this purpose $100 \mu \mathrm{L}$ of respective concentration of plasma sample was taken into polypropylene tubes and blended with $50 \mu \mathrm{L}$ of internal standard (10.0 ng.mL $\left.\mathrm{mL}^{-1}\right)$. This was superseded by addition of $100 \mu \mathrm{L}$ of $5 \mathrm{mM} \mathrm{NaH}_{2} \mathrm{PO} 4$ solution and $3.0 \mathrm{~mL}$ of ethyl acetate and vortexed around $10 \mathrm{~min}$. Then the Samples were centrifuged at $4000 \mathrm{rpm}$ for $10 \mathrm{~min}$ at $20^{\circ} \mathrm{C}$. Further, the supernatant was conveyed into 
labelled polypropylene tubes and evaporated with nitrogen gas at $40^{\circ} \mathrm{C}$. Then the samples were reconstituted with the mobile phase and vortexed for $2 \mathrm{~min}$.

\section{Chromatographic and mass spectrometry conditions}

The chromatographic separation of the analytes was accomplished at $30^{\circ} \mathrm{C}$ applying Hypersil Gold $\mathrm{C}_{18}$ $(50 \mathrm{~mm} \times 3.0 \mathrm{~mm}, 5 \mu \mathrm{m})$ column. A mixture of $10 \mathrm{~mm}$ ammonium acetate: Methanol (20:80 v/v) was used as mobile phase. $0.5 \mathrm{ml} / \mathrm{min}$ and injection volume of $20 \mu \mathrm{l}$. Liquid-liquid extraction was selected to refine the drug and internal standard triple quadruple mass spectrometer equipped with electro spray ionization and handled in positive ionization mode for tracking down and quantification of analytes and internal standards. The intensification of the source and compound parameters are Declustering potential: 40V, entrance potential: $10 \mathrm{~V}$, exit Potential: 7 , collision energy: $15 \mathrm{~V}$ for Dapagliflozin and $16 \mathrm{~V}$ for Saxagliptin .The source criteria were optimized as collision gas: 5 , ion spray voltage: $5500 \mathrm{~V}$ and temperature: $550^{\circ} \mathrm{C}$. The mass transitions were preferred as $\mathrm{m} / \mathrm{z}$ 410.2/250.6, 415.3/250.6, 316.1/272.4 and $\mathrm{m} / \mathrm{z} 318.2 / 272.3$ for quantification of DG, DGd5,SG and SGd2 respectively.

\section{Bioanalytical method validation}

The method was validated according to US food and drug administration bio analytical method validation guidelines includes system suitability, selectivity and specificity, LOQ(limit of quantification or sensitivity), injector carryover, linearity, precision and accuracy, recovery, matrix effect, dilution integrity, re-injection reproducibility, ruggedness (analyst and column), sample stability studies were carried out to prove the capability of the proposed method.

\section{Linearity}

Calibration standards were prepared to achieve linearity range of 50.00, 100.00, 500.00, 1000.00, 2000.00, 4000.00, 6000.00, 8000.00 and $10000.00 \mathrm{pg} / \mathrm{mL}$ and assayed in five replicates on five different days and the outcome were depicted in Table 1, Figure 1, 2. The present method was able to quantify lower concentration of dapagliflozin and saxagliptin. The developed standard curve displays correlation coefficient $\left(r^{2}\right)$ greater than 0.9993 with linearity range of $50.00-10000.00 \mathrm{pg} / \mathrm{mL}$ using the linear regression model $=\mathrm{ax}+\mathrm{b}$; Where, $\mathrm{y}=$ Peak area ratio of analyte, $\mathrm{X}=$ Concentration $(\mathrm{pg} / \mathrm{mL})$ of analyte in plasma, $\mathrm{a}=$ Slope, $\mathrm{b}=$ Intercept, $\mathrm{r}^{2}=$ Correlation coefficient.

\section{Accuracy and precision}

For intra batch and inter batch precision and one set contains four different concentrations of quality control standards of Lower limit QC (50.00 pg/mL), Low QC (150.00 pg/mL), Mid QC (3000.00 pg/mL) and High QC $(7000.00 \mathrm{pg} / \mathrm{mL})$ concentrations were prepared in screened human plasma and analyzed each quality control (QC) standard sinsix replicates on the same day. The standard deviation and \% coefficient of variation $(\% \mathrm{CV})$ was $\leq 15 \%$ for LQC, MQC and HQC quality control standards, except LLOQ for which it is $\leq 20 \%$. The results were depicted in Table 2.

\section{Recovery}

The extraction recovery was determined in six duplicate by comparing the extracted QC standards with un-extracted QC standards at three different concentrations of low $(150.00 \mathrm{pg} / \mathrm{mL})$, medium $(3000.00 \mathrm{pg} / \mathrm{mL})$, high $(7000.00$ $\mathrm{pg} / \mathrm{mL}) \quad \%$ recovery of dapagliflozin is $95.13 \%$

\begin{tabular}{|c|c|c|c|c|}
\hline \multicolumn{5}{|c|}{ Table 1: Calculated standard concentrations from each calibration curve for de- } \\
termination of DG, SG in spiked plasma. \\
$\begin{array}{c}\text { Spiked } \\
\text { plasma } \\
\text { concentration } \\
(\mathbf{p g} / \mathbf{m L})\end{array}$ & $\begin{array}{c}\text { Concentration } \\
\text { measured(mean) }(\mathbf{p g} / \\
\mathbf{m L}), \\
(n=5)\end{array}$ & $\begin{array}{c}\text { Precision } \\
(\mathbf{C V} \%) \\
(n=5)\end{array}$ & $\begin{array}{c}\text { Concentration } \\
\text { measured(mean) } \\
(\mathbf{p g} / \mathbf{m L}), \\
(n=5)\end{array}$ & $\begin{array}{c}\text { Precision (CV } \\
\%) \\
(n=5)\end{array}$ \\
\cline { 2 - 5 } & \multicolumn{2}{|c|}{ Dapagliflozin (DG) } & \multicolumn{2}{c|}{ Saxagliptin (SG) } \\
\hline 50.0 & $51.0 \pm 1.3$ & 2.5 & $51.2 \pm 1.0$ & 2.0 \\
\hline 100.0 & $96.6 \pm 4.7$ & 4.9 & $95.8 \pm 3.4$ & 3.5 \\
\hline 500.0 & $498.4 \pm 24.7$ & 5.0 & $495.1 \pm 26.3$ & 5.3 \\
\hline 1000.0 & $1000.0 \pm 17.1$ & 1.7 & $1010.5 \pm 28.3$ & 2.8 \\
\hline 2000.0 & $2013.0 \pm 74.6$ & 3.7 & $2019.1 \pm 70.0$ & 3.5 \\
\hline 4000.0 & $4008.4 \pm 206.6$ & 5.2 & $4067.1 \pm 224.9$ & 5.5 \\
\hline 6000.0 & $5956.5 \pm 190.7$ & 3.2 & $5628.5 \pm 735.7$ & 13.1 \\
\hline 8000.0 & $7952.2 \pm 165.6$ & 2.1 & $8162.8 \pm 191.2$ & 2.3 \\
\hline 10000.0 & $10317.1 \pm 487.6$ & 4.7 & $10440.0 \pm 521.5$ & 5.0 \\
\hline
\end{tabular}




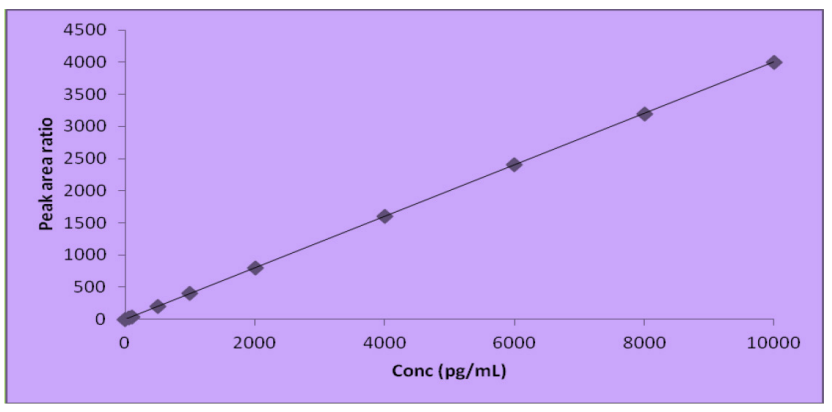

Figure 1: Calibration curve of Dapagliflozin.

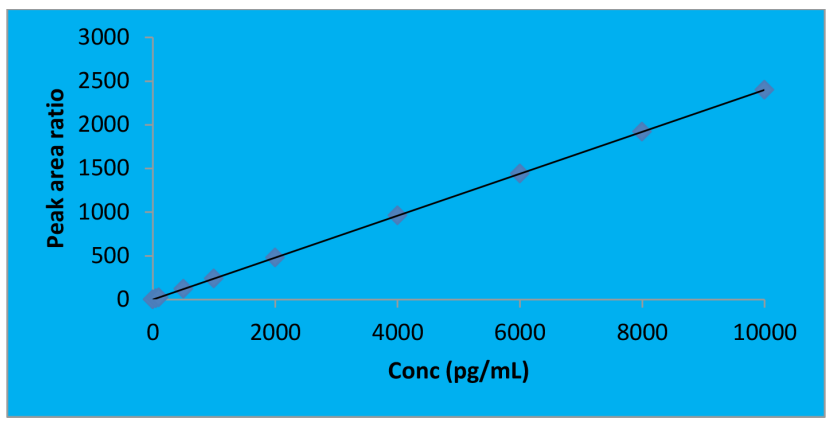

Figure 2: Calibration curve of saxagliptin.

\begin{tabular}{|c|c|c|c|c|c|c|}
\hline \multicolumn{7}{|c|}{ Dapagliflozin (DG) } \\
\hline \multirow{2}{*}{$\begin{array}{l}\text { Spiked plasma } \\
\text { concentration } \\
(\mathrm{pg} / \mathrm{mL})\end{array}$} & \multicolumn{3}{|c|}{ Within-run $(n=6)$} & \multicolumn{3}{|c|}{ Between-run $(n=30)$} \\
\hline & $\begin{array}{c}\text { Concentration } \\
\text { measured }(\mathrm{pg} / \mathrm{mL} \text { ) } \\
\text { (mean } \pm \text { S.D.) }\end{array}$ & $\begin{array}{c}\text { Precision } \\
\text { (CV \%) }\end{array}$ & $\begin{array}{c}\text { Accuracy } \\
\%\end{array}$ & $\begin{array}{c}\text { Concentration } \\
\text { measured } \\
(\mathrm{pg} / \mathrm{mL})(\text { mean } \pm \text { S.D. })\end{array}$ & $\begin{array}{c}\text { Precision } \\
\text { (CV \%) }\end{array}$ & $\begin{array}{c}\text { Accuracy } \\
\%\end{array}$ \\
\hline 50.0 & $51.4 \pm 2.3$ & 4.5 & 102.7 & $55.5 \pm 4.1$ & 7.4 & 110.6 \\
\hline 150.0 & $152.9 \pm 1.4$ & 2.2 & 105.5 & $151.9 \pm 1.7$ & 1.6 & 102.2 \\
\hline 3000.0 & $3103.8 \pm 102.0$ & 3.3 & 103.2 & $3133.0 \pm 108.2$ & 3.5 & 104.3 \\
\hline 7000.0 & $7197.1 \pm 89.9$ & 1.2 & 91.7 & $7178.7 \pm 275.5$ & 1.8 & 103.9 \\
\hline \multicolumn{7}{|c|}{ Saxagliptin (SG) } \\
\hline 50.0 & $42.4 \pm 1.0$ & 2.4 & 84.8 & $49.9 \pm 6.9$ & 3.8 & 99.4 \\
\hline 150.0 & $152.6 \pm 2.3$ & 1.4 & 106.4 & $151.5 \pm 1.6$ & 1.2 & 101.6 \\
\hline 3000.0 & $3072.4 \pm 132.6$ & 4.3 & 102.4 & $3216.1 \pm 162.6$ & 5.1 & 107.1 \\
\hline 7000.0 & $7160.1 \pm 105.8$ & 1.4 & 98.0 & $7174.3 \pm 123.9$ & 1.1 & 102.1 \\
\hline
\end{tabular}

and saxagliptin is $93.51 \%$. The standard deviation and $\%$ coefficient of variation $(\% \mathrm{CV})$ was $\leq 15 \%$ for LQC, MQC and HQC quality control standards, except LLOQ for which it is $\leq 20 \%$.The results were depicted in Table 3.

\section{Specificity and selectivity}

Ten lots of blank plasma samples were analyzed out of which six lots free from interference were selected for assessing the selectivity, specificity. Area response at the retention time of dapagliflozin and saxagliptin in the blank free from potential interference was less than $20 \%$ of the LLOQ peak areaof analyte retention time and less than $5 \%$ for internal standard retention time.

\section{Sensitivity}

Six LLOQ standards were prepared in screened plasma lot along with IS $(500.00 \mathrm{pg} / \mathrm{mL})$ and signal to noise ratio $(\mathrm{S} / \mathrm{N})$ was calculated using analyst software result given in Table 4. The mean $\mathrm{S} / \mathrm{N}$ ratio of LLOQ is $\geq 5$.

\section{Injectors carry over}

Injector carryover was assessed by injecting the extracted blank samples followed by extracted ULOQ, LLOQ samples and \%carry over was calculated the \% carry over is $0 \%$. The results were depicted in Table 5 .

\section{Matrix effect}

The blank plasma in three replicates with un-extracted mid QC (3000.00 pg/mL) were correlated with unextracted standards of the same concentration the \% CV for dapagliflozin is 1.27 and for saxagliptin is 1.20 . The results were depicted in Table 6 to 7 .

\section{Stability study}

\section{Freeze and Thaw stability}

The freeze-thaw stability was conducted by comparing the stability samples that had been frozen at $-30^{\circ} \mathrm{C}$ and thawed three times, with freshly spiked quality control samples. Six aliquots each of LQC and HQC concentration levels (150.0 -7000.0 $\mathrm{pg} / \mathrm{mL})$ were used for the 


\begin{tabular}{|c|c|c|}
\hline $\begin{array}{l}\text { Conc. } \\
\text { (pg/mL) }\end{array}$ & $\begin{array}{c}\text { Extracted DG } \\
\text { Peak area }\end{array}$ & $\begin{array}{c}\text { Unextracted DG } \\
\text { Peak area }\end{array}$ \\
\hline \multirow{6}{*}{$\begin{array}{c}\text { Low QC } \\
(150.00 \mathrm{pg} / \mathrm{mL})\end{array}$} & 140596 & 140250 \\
\hline & 140856 & 135679 \\
\hline & 131252 & 141076 \\
\hline & 130767 & 128436 \\
\hline & 141955 & 148649 \\
\hline & 135390 & 130686 \\
\hline $\mathrm{N}$ & 6 & 6 \\
\hline$\%$ Recovery & 99.67 & \\
\hline $\mathrm{SD}( \pm)$ & 4.45 & \\
\hline$\% \mathrm{CV}$ & 4.46 & \\
\hline \multirow{6}{*}{$\begin{array}{c}\text { Medium QC } \\
(3000.00 \mathrm{pg} / \mathrm{mL})\end{array}$} & 1997047 & 2357708 \\
\hline & 1920067 & 2224569 \\
\hline & 1934526 & 2166896 \\
\hline & 1910517 & 2132067 \\
\hline & 1892531 & 2044042 \\
\hline & 1822156 & 2093316 \\
\hline $\mathrm{N}$ & 6 & 6 \\
\hline \% Recovery & 88.26 & \\
\hline $\mathrm{SD}( \pm)$ & 2.81 & \\
\hline$\% \mathrm{CV}$ & 3.18 & \\
\hline \multirow{6}{*}{$\begin{array}{c}\text { High QC } \\
(7000.00 \mathrm{pg} / \mathrm{mL})\end{array}$} & 4825281 & 4755582 \\
\hline & 4746815 & 5555112 \\
\hline & 4841834 & 5048175 \\
\hline & 4731244 & 5138559 \\
\hline & 5641543 & 5230888 \\
\hline & 5052374 & 4948616 \\
\hline $\mathrm{N}$ & 6 & 6 \\
\hline$\%$ Recovery & 97.47 & \\
\hline $\mathrm{SD}( \pm)$ & 6.06 & \\
\hline$\% \mathrm{CV}$ & 6.37 & \\
\hline Mean \%Recovery & 95.13 & \\
\hline Mean \% CV & 6.37 & \\
\hline
\end{tabular}

freeze-thaw stability evaluation. The $\%$ accuracy for freeze stability is $104.3 \%$ for dapagliflozin, $106.4 \%$ for saxagliptin and thaw stability is $90.4 \%$ for dapagliflozin, $94.3 \%$ for saxagliptin .Mean \% accuracy was found to be within limits $85-115 \%$. The results were depicted in Table 8.

\section{Auto sampler stability for $\mathbf{7 0 . 0 \mathrm { h }}$}

The auto sampler sample stability was evaluated by comparing the extracted plasma samples that were injected immediately (time $0 \mathrm{~h}$ ), with the samples that were reinjected after storing in the auto sampler at $20^{\circ} \mathrm{C}$ for $70.0 \mathrm{~h}$. The reinjection reproducibility was evaluated by comparing the extracted plasma samples that were injected immediately (time $0 \mathrm{~h}$ ), with the samples that were re-injected after storing in the auto sampler at $20^{\circ} \mathrm{C}$ for $70 \mathrm{~h}$, each of LQC and HQC concentration levels

\section{Table 4: Sensitivity of DG and SG.}

\begin{tabular}{|c|c|c|c|c|}
\hline \multirow{2}{*}{$\begin{array}{c}\text { Blank human } \\
\text { Plasma } \\
\text { B. No }\end{array}$} & \multicolumn{2}{|c|}{ GP } & \multicolumn{2}{|c|}{ ES } \\
\hline & $\begin{array}{c}\text { LLOQ } \\
\text { peak } \\
\text { area }\end{array}$ & $\begin{array}{l}\text { LLOQ } \\
\text { S/N ratio }\end{array}$ & $\begin{array}{c}\text { LLOQ } \\
\text { peak area }\end{array}$ & $\begin{array}{l}\text { LLOQ } \\
\text { S/N ratio }\end{array}$ \\
\hline \multirow{6}{*}{$\begin{array}{c}\text { 55-17869 A } \\
\text { (Lot.No-1) }\end{array}$} & 17565 & 26.4 & 21787 & 46.7 \\
\hline & 26347 & 27.3 & 18362 & 26.3 \\
\hline & 21763 & 35.5 & 20536 & 38.5 \\
\hline & 27688 & 34.5 & 33373 & 43.1 \\
\hline & 27880 & 34.4 & 32610 & 43.6 \\
\hline & 24884 & 33.60 & 30884 & 43.20 \\
\hline $\mathrm{N}$ & 6 & 6 & 6 & 6 \\
\hline Mean & & 32.00 & & 40.20 \\
\hline
\end{tabular}

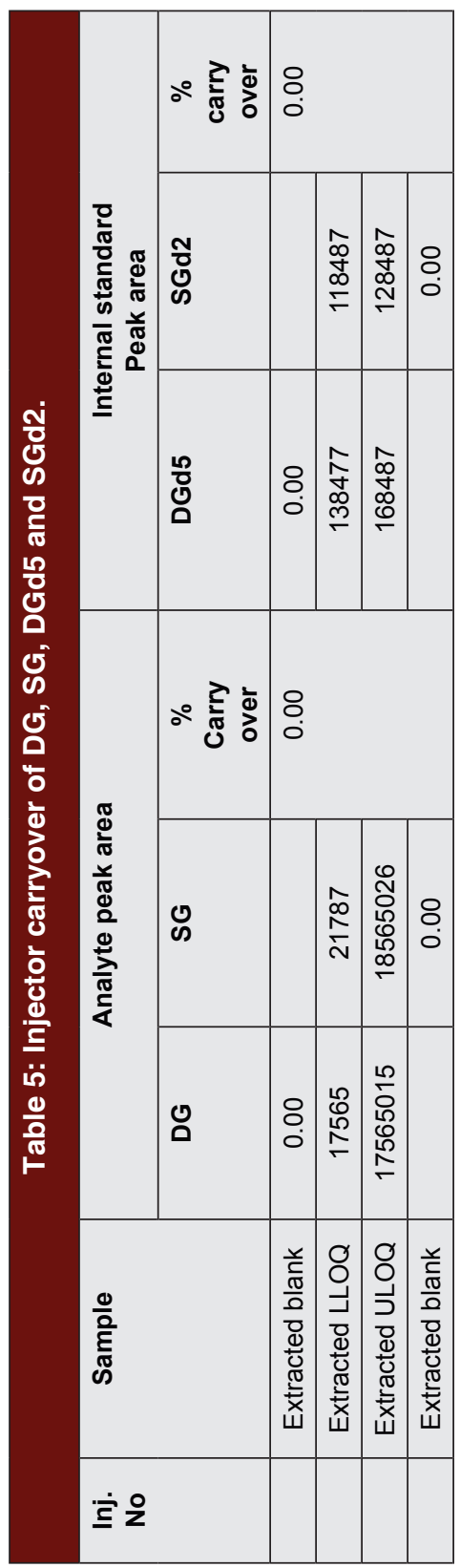


Table 6: Assessment of matrix effect of Dapagliflozin.

\begin{tabular}{|c|c|c|c|c|}
\hline \multirow{2}{*}{$\begin{array}{c}\text { Blank } \\
\text { human } \\
\text { Plasma } \\
\text { Lot. No }\end{array}$} & \multirow{2}{*}{$\begin{array}{c}\text { Blank } \\
\text { human } \\
\text { Plasma } \\
\text { B. No }\end{array}$} & \multicolumn{3}{|c|}{ Mid QC $(3000.00 \mathrm{pg} / \mathrm{mL})$} \\
\hline & & $\begin{array}{c}\text { Extracted } \\
\text { Peak } \\
\text { area ratio }\end{array}$ & $\begin{array}{c}\text { Unextracted } \\
\text { Peak } \\
\text { area ratio }\end{array}$ & $\begin{array}{l}\text { Matrix } \\
\text { factor }\end{array}$ \\
\hline & \multirow[t]{3}{*}{$55-17869 \mathrm{~A}$} & 1.410000 & 1.944950 & 0.724954 \\
\hline & & 1.331450 & 1.896400 & 0.702093 \\
\hline & & 1.417700 & 1.914400 & 0.740545 \\
\hline & \multirow[t]{3}{*}{$55-17985 \mathrm{~A}$} & 1.421050 & 1.874650 & 0.758035 \\
\hline & & 1.387600 & 1.928050 & 0.719691 \\
\hline & & 1.334550 & 1.863950 & 0.715980 \\
\hline & \multirow[t]{3}{*}{$55-17600 \mathrm{~A}$} & 1.410000 & 1.894950 & 0.744083 \\
\hline & & 1.331450 & 1.945950 & 0.684216 \\
\hline & & 1.417700 & 1.875000 & 0.756107 \\
\hline & \multirow[t]{3}{*}{$55-17975 \mathrm{~A}$} & 1.421050 & 1.820900 & 0.780411 \\
\hline & & 1.387600 & 1.817200 & 0.763592 \\
\hline & & 1.334550 & 1.844050 & 0.723706 \\
\hline
\end{tabular}

(150.0 - 7000.0 pg/mL). The \%accuracy for dapagliflozin is 108.2- $90.4 \%$ and for saxagliptin is $107.8-95.9 \%$. Mean $\%$ accuracy was found to be within limits $85-115 \%$. The results were depicted in Table 8.

\section{Bench top stability at room temperature for $9.5 \mathrm{~h}$}

The stability of spiked human plasma samples stored at room temperature bench top stability using standard stock solutions of DG, SG, DGd5, SGd2 (ST stability samples) were set aside on the bench up to $9.5 \mathrm{~h}$ and compared with newly prepared stock solutions each of LQC and HQC concentration levels (150.0-7000.0 pg/ $\mathrm{mL})$. The \% accuracy was found to be $98.9-81.5 \%$ for dapagliflozin and $104.2-92.6 \%$ for saxagliptin. The $\%$ accuracy was found to be within limits 85-115\%.The results were depicted in Table 8.

\section{Long term stability studies}

For long term stability evaluation the concentrations obtained after 91 days were compared with initial concentrations each of LQC and HQC concentration

\begin{tabular}{|c|c|c|c|c|}
\hline \multirow{2}{*}{$\begin{array}{l}\text { Blank human } \\
\text { Plasma Lot. No }\end{array}$} & \multirow{2}{*}{$\begin{array}{c}\text { Blank human Plasma } \\
\text { B. No }\end{array}$} & \multicolumn{3}{|c|}{ Mid QC $(3000.00 \mathrm{pg} / \mathrm{mL})$} \\
\hline & & $\begin{array}{c}\text { Extracted } \\
\text { Peak } \\
\text { area ratio }\end{array}$ & $\begin{array}{c}\text { Unextracted } \\
\text { Peak } \\
\text { area ratio }\end{array}$ & $\begin{array}{l}\text { Matrix } \\
\text { factor }\end{array}$ \\
\hline \multirow[t]{3}{*}{1} & \multirow[t]{3}{*}{$55-17869$ A } & 1.155650 & 1.660350 & 0.696028 \\
\hline & & 1.168150 & 1.577550 & 0.740484 \\
\hline & & 1.118600 & 1.614800 & 0.692717 \\
\hline \multirow[t]{3}{*}{2.} & \multirow[t]{3}{*}{$55-17985 \mathrm{~A}$} & 1.187000 & 1.595300 & 0.744061 \\
\hline & & 1.181600 & 1.582550 & 0.746643 \\
\hline & & 1.132300 & 1.556150 & 0.727629 \\
\hline \multirow[t]{3}{*}{3.} & \multirow[t]{3}{*}{$55-17600 \mathrm{~A}$} & 1.155650 & 1.592550 & 0.725660 \\
\hline & & 1.168150 & 1.541650 & 0.757727 \\
\hline & & 1.118600 & 1.616100 & 0.692160 \\
\hline \multirow[t]{3}{*}{4.} & \multirow[t]{3}{*}{$55-17975 \mathrm{~A}$} & 1.187000 & 1.605000 & 0.739564 \\
\hline & & 1.181600 & 1.614700 & 0.731777 \\
\hline & & 1.132300 & 1.582400 & 0.715559 \\
\hline \multirow[t]{3}{*}{5.} & \multirow[t]{3}{*}{$55-17978 \mathrm{~A}$} & 1.155650 & 1.557500 & 0.741990 \\
\hline & & 1.168150 & 1.580400 & 0.739148 \\
\hline & & 1.118600 & 1.596150 & 0.700811 \\
\hline \multirow[t]{3}{*}{6.} & \multirow[t]{3}{*}{$55-18013 \mathrm{~A}$} & 1.187000 & 1.715600 & 0.691886 \\
\hline & & 1.181600 & 1.599750 & 0.738615 \\
\hline & & 1.132300 & 1.667350 & 0.679102 \\
\hline \multicolumn{2}{|c|}{$\mathrm{N}$} & \multirow{4}{*}{\multicolumn{2}{|c|}{$\begin{array}{c}0.722309 \\
0.024 \\
1.20\end{array}$}} & 18 \\
\hline \multicolumn{2}{|c|}{ Mean } & & & \\
\hline \multicolumn{2}{|c|}{$\mathrm{SD}( \pm)$} & & & \\
\hline \multicolumn{2}{|c|}{$\% \mathrm{CV}$} & & & \\
\hline
\end{tabular}




\begin{tabular}{|c|c|c|c|c|c|}
\hline Stability experiments & $\begin{array}{l}\text { Storage } \\
\text { condition }\end{array}$ & $\begin{array}{c}\text { Spiked plasma } \\
\text { concentration (pg/ } \\
\mathrm{ml})\end{array}$ & $\begin{array}{c}\text { Concentration } \\
\text { measured } \\
(n=6) \\
\text { Mean } \pm \text { SD }\end{array}$ & $\begin{array}{c}\text { CV (\%) } \\
(n=6)\end{array}$ & $\begin{array}{c}\text { Accuracy } \\
(\%)\end{array}$ \\
\hline \multicolumn{6}{|c|}{ Dapagliflozin (DG) } \\
\hline \multirow{2}{*}{$\begin{array}{c}\text { Bench top } \\
\text { (Room temperature) }\end{array}$} & \multirow{2}{*}{$\begin{array}{l}\mathrm{RT} \\
61 \mathrm{hr}\end{array}$} & 150.0 & $148.3 \pm 8.1$ & 5.5 & 98.9 \\
\hline & & 7000.0 & $6728.3 \pm 206.3$ & 3.1 & 81.5 \\
\hline \multirow{2}{*}{$\begin{array}{c}\text { Processed } \\
\text { (extracted sample) }\end{array}$} & \multirow{2}{*}{$\begin{array}{c}\text { Auto sampler } \\
70 \mathrm{hr}\end{array}$} & 150.0 & $162.3 \pm 2.4$ & 1.5 & 108.2 \\
\hline & & 7000.0 & $7536.7 \pm 294.5$ & 3.9 & 90.4 \\
\hline \multirow[t]{2}{*}{ Freeze and Thaw stability } & \multirow{2}{*}{$\begin{array}{c}-30^{\circ} \mathrm{C} \\
\text { Cycle-3 }\end{array}$} & 150.0 & $156.5 \pm 4.0$ & 2.5 & 104.3 \\
\hline & & 7000.0 & $7381.7 \pm 173.4$ & 2.3 & 90.4 \\
\hline \multirow[t]{2}{*}{ Long term stability } & \multirow[t]{2}{*}{$-30^{\circ} \mathrm{C}, 91$ days } & 50.0 & $160.3 \pm 13.2$ & 8.2 & 106.9 \\
\hline & & 7000.0 & $7450.0 \pm 229.1$ & 3.1 & 90.5 \\
\hline \multicolumn{6}{|c|}{ Saxagliptin(SG) } \\
\hline \multirow{2}{*}{$\begin{array}{c}\text { Bench top } \\
\text { (Room temperature) }\end{array}$} & \multirow{2}{*}{$\begin{array}{c}\mathrm{RT} \\
61 \mathrm{hr}\end{array}$} & 150.0 & $156.3 \pm 8.7$ & 5.6 & 104.2 \\
\hline & & 7000.0 & $7411.7 \pm 213.7$ & 2.9 & 92.6 \\
\hline \multirow{2}{*}{$\begin{array}{c}\text { Processed } \\
\text { (extracted sample) }\end{array}$} & \multirow{2}{*}{$\begin{array}{l}\text { Auto sampler } \\
70 \mathrm{hr}\end{array}$} & 150.0 & $161.7 \pm 4.9$ & 3.0 & 107.8 \\
\hline & & 7000.0 & $7675.0 \pm 473.5$ & 6.2 & 95.9 \\
\hline \multirow[t]{2}{*}{ Freeze and Thaw stability } & \multirow{2}{*}{$\begin{array}{l}-30^{\circ} \mathrm{C} \\
\text { Cycle-3 }\end{array}$} & 150.0 & $159.7 \pm 7.6$ & 4.7 & 106.4 \\
\hline & & 7000.0 & $7540.0 \pm 323.0$ & 4.3 & 94.3 \\
\hline \multirow[t]{2}{*}{ Long term stability } & \multirow[t]{2}{*}{$-30^{\circ} \mathrm{C}, 91$ days } & 50.0 & $159.0 \pm 6.3$ & 4.0 & 106.0 \\
\hline & & 7000.0 & $7608.3 \pm 297.2$ & 3.9 & 95.1 \\
\hline
\end{tabular}

levels (150.0 -7000.0 pg/mL). The \% accuracy was found to be 106.9-90.5\% for dapagliflozin and 106.0$95.1 \%$ for saxagliptin. The \% accuracy was found to be within limits $85-115 \%$.The results were depicted in Table8.

\section{RESULTS}

Distinctive organic solvents and buffers were optimized to excerpt DG and SG from plasma samples. Optimized method is methanol and ammonium acetate buffer with concentration $10 \mathrm{mM}$. After a course of trials, ethyl acetate and $5 \mathrm{mM} \mathrm{NaH} \mathrm{NO}_{2}$ buffer were preferred as applicable due to immense recovery efficiency and matrix free interference.

The best results were obtained with ratio $(20: 80 \%)$ of mobile phase composition. Hypersil Gold $\mathrm{C}_{18}(50 \mathrm{~mm} \times$ $3.0 \mathrm{~mm}, 5 \mu \mathrm{m}$ ) column at $30^{\circ} \mathrm{c}$ was used to reduce the run time and retention time Figure 3,4. Low volume of flow rate $0.5 \mathrm{ml} / \mathrm{min}$ was selected to reduce the usage of mobile phase. The MS optimization was achieved by direct infusion of solutions of SG, DG, DGd5 and SGd2 into the ESI source of the mass spectrometer. The mass transitions were preferred as $\mathrm{m} / \mathrm{z} 410.2 / 250.6,415.3 / 250.6$, $316.1 / 272.4$ and $\mathrm{m} / \mathrm{z} 318.2 / 272.3$ for quantification of DG, DGd5, SG and SGd2respectively mass transi- tions are depicted in mass spectrums Figures 5, 6. The method showed excellent linearity over the concentration range of $50.00-10000.00 \mathrm{pg} / \mathrm{mL}$ for both the analytes, with correlation coefficient value $\geq 0.999$.Intra and inter day precision and accuracy for dapagliflozin and saxagliptin standard deviation and \% coefficient of variation $(\% \mathrm{CV})$ was $\leq 15 \%$ for $\mathrm{LQC}, \mathrm{MQC}$ and $\mathrm{HQC}$ quality control standards, except LLOQ for which it is $\leq 20 \%$. The extraction recovery was determined at three different concentrations of low $(150.00 \mathrm{pg} / \mathrm{mL})$, medium(3000.00pg/mL), high $(7000.00 \mathrm{pg} / \mathrm{mL}) \quad \%$ recovery of dapagliflozin is $95.13 \%$ and saxagliptin is 93.51\%.six lots free from interference were selected for assessing the selectivity, specificity area response at the retention time of dapagliflozin and saxagliptin in the blank free from potential interference was less than $20 \%$ of the LLOQ peak area of analyte retention time and less than $5 \%$ for internal standard retention time. The sensitivity of the developed method was determined from signal to noise ratio $(\mathrm{S} / \mathrm{N})$ which was calculated using analyst software result given in Table 4 . The mean $\mathrm{S} / \mathrm{N}$ ratio of LLOQ is $\geq 5$.Injector carryover was assessed by injecting the extracted blank samples followed by extracted ULOQ, LLOQ samples the carryover was found to be $0 \%$.There was null or negligible matrix effect. Freeze and thaw stability studies using the 


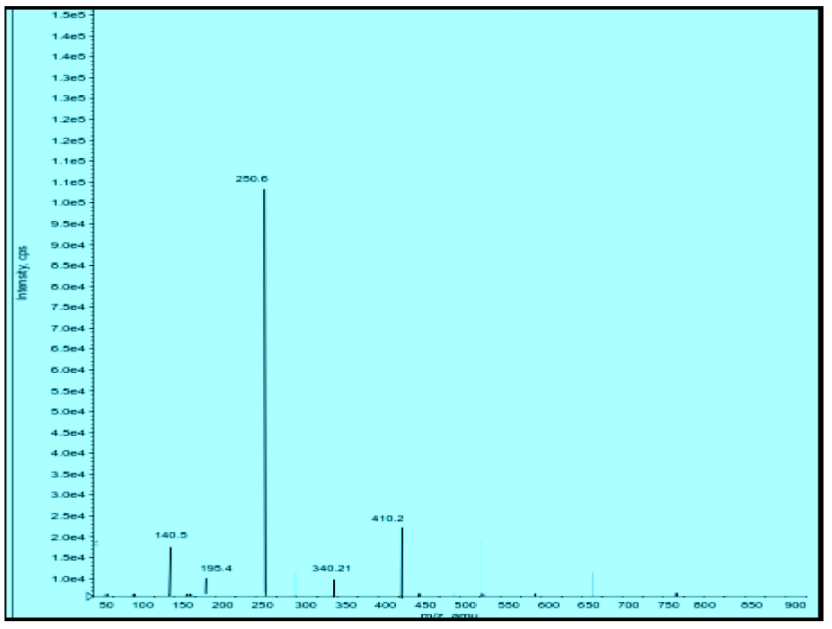

Figure 3: Parent and Product ion mass spectrum of Dapagliflozin.

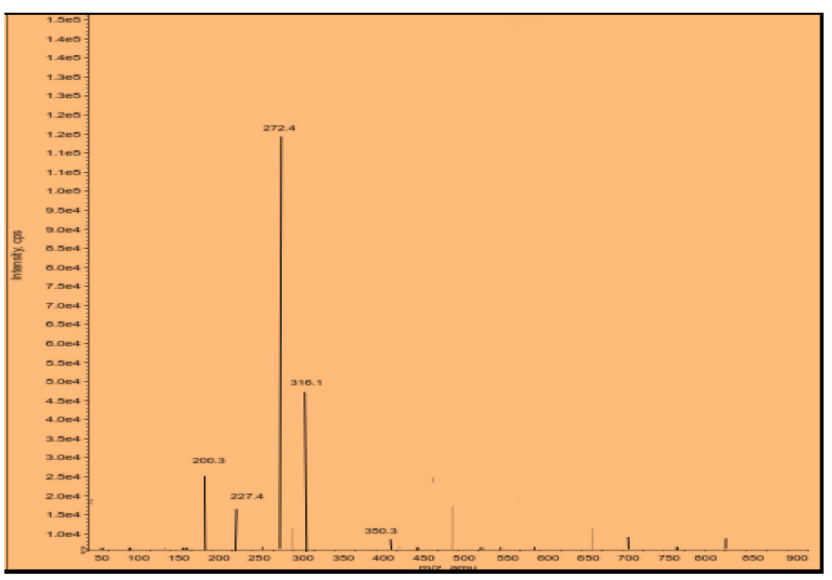

Figure 4: Parent and Product ion mass spectrum of Saxagliptin.

frozen samples at $-30^{\circ} \mathrm{C}$ determined at low and high QC samples showed acceptable limits. The auto sampler sample stability was evaluated for the reinjection reproducibility $20^{\circ} \mathrm{C}$ for $70 \mathrm{~h}$, each of LQC and HQC concentration levels. The \% accuracy for dapagliflozin is $108.2-90.4 \%$ and for saxagliptin is $107.8-95.9 \%$. The bench top stability using standard stock solutions of DG, SG, DGd5, SGd2 (ST stability samples) were set aside on the bench up to $9.5 \mathrm{~h}$ and compared with newly prepared stock solutions each of LQC and HQC concentration levels. The $\%$ accuracy was found to be $98.9-81.5 \%$ for dapagliflozin and $104.2-92.6 \%$ for saxagliptin. Long term stability evaluation the concentrations obtained after 91 days were compared with initial concentrations each of LQC and HQC concentration levels $(150.0-7000.0 \mathrm{pg} / \mathrm{mL})$.The \% accuracy was found to be $106.9-90.5 \%$ for dapagliflozin and 106.0-95.1\% for saxagliptin.

\section{DISCUSSION}

The optimized method showed good chromatographic separation and mass transitions with methanol and ammonium acetate buffer $10 \mathrm{mM}$ concentration because of its high volatility as it is required in mass spectrometry analysis. Hypersil Gold $C_{18}(50 \mathrm{~mm} \times 3.0 \mathrm{~mm}, 5 \mu \mathrm{m})$ column at $30^{\circ} \mathrm{C}$ was used for column efficiency. The basic parameters like ionization type, temperature, voltage, gas parameters such as nebulizer and heater gases, compound parameters like DP, EP, FP, CE and CXP were optimized to obtain a better spray shape and ionization to form the corresponding productions from the protonated SG, DG, DGd5 and SGd2 molecules. The best fit for calibration curve of chromatographic response verses concentration is determined by linear regression model. The data of intra and inter day precision and accuracy for dapagliflozin and saxagliptin from QC samples are summarized in Table 2. The extraction recovery was good, consistent and precise, reproducible with the optimized extraction procedure. The results were depicted in Table 3. Area response at the retention time of dapagliflozin and saxagliptin in the blank free from potential interference was less than $20 \%$ of the LLOQ peak area of analyte retention time and less than $5 \%$ for internal standard retention time. The injector carry over test showed $0 \%$ carry over for the extracted blank samples followed by extracted ULOQ, LLOQ samples. Freeze and thaw stability studies frozen at $-30^{\circ} \mathrm{C}$ and thawed three times showed acceptable limits $85-115 \%$. The auto sampler sample stability $20^{\circ} \mathrm{C}$ for $70 \mathrm{~h}$, each of LQC and HQC concentration levels showed Mean \% accuracy within limits 85-115\%.Bench top stability using standard stock solutions of DG, SG, DGd5, SGd2 (ST stability samples) were set aside on the bench up to $9.5 \mathrm{~h}$ and compared with newly prepared stock solutions each of LQC and HQC concentration levels. The $\%$ accuracy was found to be within limits $85-115 \%$. Long term stability evaluation was performed for 91 days and compared with initial concentrations each of LQC and HQC concentration levels. The \% accuracy was found to be within limits $85-115 \%$.

\section{CONCLUSION}

In conclusion, the recommended research work is highly specific due to the inherent selectivity of tandem mass spectrometry and has significant prevalence over other described methods in previously. The proposed method is able to simultaneously estimate dapagliflozin and saxagliptin in human plasma at very low concentration in $\mathrm{pg} / \mathrm{mL}$. High recovery with liquid -liquid extraction method and lesser retention time is time saving and 
cost effective when compared with other methods. The simplicity of the method allows for application in laboratories, presents a valuable tool for bioavailability, bioequivalence, pharmacokinetic studies.

\section{ACKNOWLEDGEMENT}

Authors are thankful to the principal of Niramala College of pharmacy for necessary support and research facilities.

\section{CONFLICT OF INTEREST}

No conflicts of interest.

\section{ABBREVATIONS}

LQC: Lower quality control; HQC: Higher quality control; LLOQ: Lower Limit of quantification; ULOQ: Upper Limit of Quantification.

\section{REFERENCES}

1. Erica O, Jerry RB. Type2 Diabetes Symptoms, Signs, Diet an Treatment. Available from: https://www.medicinenet.com/type_2_diabetes/article.htm. (Lastcited on 2017 May 21)

2. Dapagliflozin Drug Bank. Available from:https://www.drugbank.ca/drugs/ DB06292. htm. (Last cited on 2017 June 10)

3. Mitali V, Verma CJ, Patel. Development and stability indicating HPLC method for dapagliflozin in API and pharmaceutical dosage form. Int J App Pharm. 2017;9(5):33-41.

4. Aubrey AF, Gu H, Mangier R, Morgan L. Validated LC-MS/MS methods for the determination of dapagliflozin, a sodium-glucose co-transporter 2 inhibitor in normal and ZDF rat plasma. Bioanalysis. 2010;2(12):2001-9

5. Patel CJ. Simultaneous estimation of dapagliflozin in api and pharmaceutical dosage form by development and stability indicating hplc method. WJPPS. 2017;20177-01.

6. Mohammad Y. A validated stability indicating high-performance liquid chromatographic method for simultaneous determination of metformin $\mathrm{HCL}$ and dapagliflozin in bulk drug and tablet dosage form. Asian J Pharm Clin Res. 2015;8(3):320-6.

7. Priyanka A. Shah, Jaivik S. LC-MS/MS analysis of metformin, saxagliptin and 5-hydroxy saxagliptin in human plasma and its pharmacokinetic study with a fixed-dose formulation in healthy Indian subjects: Quantitation of

\section{PICTORIAL ABSTRACT}

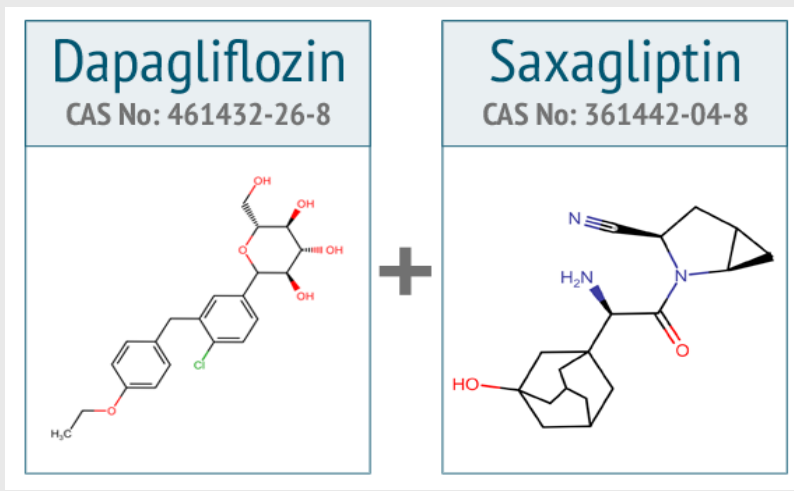

metformin, saxagliptin and 5-hydroxy saxagliptin. Biomed Chromatogram. 2017;31(3):e3809.

8. Laís ES, Ana IPM. Stability indicating RP-LC-PDA method for the quantitative analysis of saxagliptin in pharmaceutical dosage form. Braz J Pharm. 2015;51(2):461-6.

9. Jing-Wen G. Development of a rapid UPLC-MS/MS method for quantification of saxagliptin in rat plasma and application to pharmacokinetic study. Biomed Chromatogr. 2012;26(12):1482-7

10. Bioanalytical Method Validation. Available from: https://www.fda.gov/ downloads/Drugs/Guidance/ucm070107.pdf. (Last cited on 2017 June 15)

11. Sena C, Ali RA. A validated high performance liquid chromatography method for the determination of saxagliptin and metforminin bulk and stability indicating study. J Anal Bioanal Tech. 2014;S12.

12. Abdel-Ghany MF, Abdel-Aziz O. Stability-Indicating Liquid Chromatographic Method for Determination of Saxagliptin and Structure Elucidation of the Major Degradation Products Using LC-MS. Journal of Chromatographic Science. 2015;53(4):554-64.

13. Jitendra D, Sundeep K, Sajal KJ. A New RP-HPLC Method Development and Validation of Dapagliflozin in Bulk and Tablet Dosage Form. Int J Drug Dev and Res. 2017;9(2):48-51.

14. Khyati JP, Ankit BC, Shweta MB. Stability indicating RP-HPLC method development and validation for estimation of dapagliflozin and metformin. HCL. 2017;6(9):796-809.

15. Sarath N, Seshagiri RJVLN. A Stability Indicating RP-HPLC Method for Simultaneous Estimation of Dapagliflozin and Saxagliptin in Combined Tablet Dosage Forms. Inventi Rapid: Pharm Analysis and Quality Assurance. 2017;(4):1-11

16. Manasa S, Dhanalakshmi K, Nagarjunareddy G. Development and validation of a RP-HPLC method for the estimation of dapagliflozin in api. IJPSR. 2014;5(12):5394-7.

17. Batta N, Pilli NR, Vurimindi HB. A rapid and sensitive LC-MS/MS assay for the determination of saxagliptin and its active metabolite 5-hydroxy saxagliptin in human plasma and its application to a pharmacokinetic study. Drug Res (Stuttg). 2015;65(3):133-40.

18. Shah PA, Shah JV, Sanyal M, Shrivastav PS. LC-MS/MS analysis of metformin, saxagliptin and 5-hydroxy saxagliptin in human plasma and its pharmacokinetic study with a fixed-dose formulation in healthy Indian subjects. Biomed Chromatogr. 2017:31(3).

19. Sarif NK, Jane TJ. Stability indicating validated RP-HPLC technique for the analysis of multicomponent anti-diabetic drug combos in pharmaceutical dosage forms. Karbala International Journal of Modern Science. 2015;(1):39-48.

20. Pawanjeet JC, Balaji M, Srinivasarao V. Devolpment and validation of simple stability indicating RP-HPLC method foranalysis of saxagliptin and its forced degradation impurities in bulk drug and pharmaceutical dosage form. Int $\mathrm{J}$ Res Dev Pharm L Sci. 2014;3(3):993-1003.

21. Shailesh TP, Pratik KP, Marmik P, Vijendra BC, Chhaganbhai. Development and validation of the liquid chromatography-tandem mass spectrometry method for quantitative estimation of candesartan from human plasma. Pharm Methods. 2011;2(2):130-4.

\section{Summary}

The proposed method is able to simultaneously estimate dapagliflozin and saxagliptin in human plasma at very low concentration in $\mathrm{pg} / \mathrm{mL}$. High recovery with liquid -liquid extraction method and lesser retention time is time saving and cost effective when compared with other methods. The simplicity of the method allows for application in laboratories, presents a valuable tool for bioavailability, bioequivalence, pharmacokinetic studies. 


\section{About Authors}

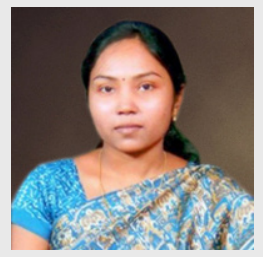

Swapna Goday: I am working as assistant professor, department of pharmaceutical analysis. am having 5 years 5 months experience in teaching. i am having 10 paper publications as well.

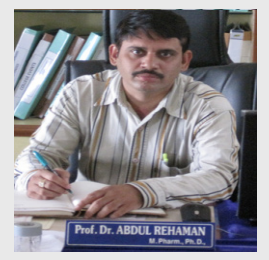

Abdul Rahaman Sk: I am working as Principal \& Professor in our college since May, 2013. I have eleven (14) years of teaching and research experience. I worked as Research Associate in Divis Research Centre (DRC) for 2 years 2 months and served as Assistant professor for 4 yrs 2 months in KVSR Siddhartha College of Pharmaceutical Sciences, Vijayawada, Andhra Pradesh, India and worked as Professor \& Head about 4 years in our institution. I have contributed two (2) patents in the field of Pharmaceutical Chemistry and filed 2 more patents to Indian patent office, Chennai. I have participated 27 conferences and presented 14 research papers. I bagged five (05) prizes for oral and poster presentations. In my Professional career I have guided $12 \mathrm{M}$. Pharmacy and $58 \mathrm{~B}$. Pharmacy candidates in the form of projects. Presently guiding $7 \mathrm{Ph}$.D. and $6 \mathrm{M}$. Pharmacy and 4 graduation candidates. I am the reviewer for Springers, Elsevier publishers to review research articles in the field of Pharmacy. Life member of APTI (Association of Pharmacy Teachers of India), IAO (International Accrediation of Organization), AIC (Associate in chemistry).

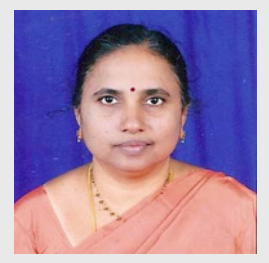

Prameelarani Avula: I am working as professor and Principal of ANU College of Pharmaceutical sciences, Guntur. I Completed masters from Andhra University. i am having 24 years of experience in teaching. I am having more than 30 paper publications in national and international journals.

Cite this article: Goday S, Rahaman ASK, Prameelarani A. Development and Validation of a LC-ESI-MS/MS Based Bioanalytical Method for Dapagliflozin and Saxagliptin in Human Plasma. Indian $\mathrm{J}$ of Pharmaceutical Education and Research. 2018;52(4 Suppl 2):S277-S286. 